\title{
Images and Evidence: \\ Human Trafficking, Auditing, and the Production of Illicit Markets in Southeast Asia and Beyond
}

\author{
Johan Lindquist
}

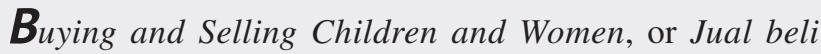
anak dan perempuan, is an Indonesian documentary film from 2003 made by the Jakarta-based nongovernmental organization (NGO) Yayasan Jurnal Perempuan (YJP; Women's Journal Foundation). The film, widely used at conferences and workshops dealing with countertrafficking in Indonesia and neighboring countries, was funded by international donors such as the United States Agency for International Development and in part edited and produced by a former British Broadcasting Corporation (BBC) journalist from England.

The film begins with the United Nations definition of trafficking and a statement that women and children are increasingly bought and sold in Indonesia today. It focuses on female prostitutes on the Indonesian island of Batam, an export-processing zone located opposite Singapore. The narrator, Gadis Arivia, one of the filmmakers, the director of YJP, and a well-known activist in Indonesia, tells viewers that men from Singapore come to Batam to buy sex. She claims that "according to local NGO workers," most of the women are trafficked and underage, since Singaporean clients often prefer young girls. The bulk of the report is

Earlier versions of this essay were presented at the University of Toronto, the University of Vienna, the National University of Singapore, Brown University, and the 2005 annual meeting of the American Anthropological Association. I thank Ken MacDonald, Thomas Fillitz, Brenda Yeoh, Shirlena Huang, and Kay Warren for their invitations and intellectual engagement. I am particularly grateful to Meg McLagan, Maple Razsa, Rachel Silvey, Dilip Gaonkar, and the journal's editorial committee for their comments on the written versions of the essay. Finally, thanks to the Swedish Research Council for financial support.
\end{abstract}

Public Culture 22:2 DOI 10.1215/08992363-2009-026 
based on interviews with Lara, who is fourteen; Leni, sixteen; Weni, seventeen; and Adissa, thirty. To protect their anonymity, viewers are never allowed to see their faces.

These testimonials are interspersed with interviews with Lola Wagner, the Indonesian director of Yayasan Mitra Kesehatan dan Kemanusiaan (YMKK; Partnership in Health and Humanity Foundation), a local NGO on Batam, as she works in front of her computer and speaks at a local workshop. Lola offers figures and describes the extent of human trafficking on Batam before the narrator explains that women do not trust local authorities and therefore do not attempt to escape. The film reaches its climax with the words of a former migrant to Malaysia who says, "We have no rights so just don't be tempted" (to migrate, that is), before concluding, "If you hear of anyone getting trafficked, get in touch with YJP."

Saleemah Ismail, the president of the Singapore chapter of the United Nations Development Fund for Women (UNIFEM), first saw Buying and Selling Children and Women in 2004 at a conference on Batam convened by the International Catholic Migration Commission, one of the international NGOs that implements the U.S. government's Trafficking in Persons program in Indonesia. The film affected Saleemah deeply, particularly the interview with Lara, the fourteen-yearold prostitute. When she watched it, she told me, "I saw my neighbors, cousins, and friends. When you see her face, she looks like us. She is every girl I grew up with."' After viewing the film, Saleemah realized that UNIFEM Singapore in its cross-border collaborations should focus more exclusively on trafficking issues. Why should YMKK (which UNIFEM was funding) concentrate on issues such as "reproductive health," she asked me rhetorically, when there were "more pressing needs"? These pressing needs were made evident in the film: women and children on Batam - just across the border from Singapore - were being sold into prostitution.

\section{Producing Markets}

Human trafficking, we are increasingly told, is the fastest-growing illegal market in the world. Along with terrorism and drug trafficking it is - as one observer phrases it - "one of the three "evils' that haunts the globe" (Kempadoo et al. 2005: vii). On the fringes of these claims, which have come to characterize mainstream public opinion in Europe and North America, there are discussions among

1. Saleemah Ismail, interview by the author, Singapore, June 19, 2005. 
academics and policy experts about how to define human trafficking, the extent of the problem, and how to refine the tools used to measure it (Bales 2005; Laczko 2005; Savona and Stefanizzi 2007).

Studies concerning black markets generally lack the empirical basis that characterizes the analysis of legal and formal markets. Certainly, the occasional economists who use satellite images to study the expansion and contraction of Afghan poppy fields, or who stumble on a meticulous Chicago gang leader who masters the art of accounting (Levitt and Venkatesh 2000), suggest creative exceptions; yet when dealing with human trafficking most experts agree that the production of statistics faces major obstacles since victims are a "hidden population" (Laczko 2005: 5).

However, in contemporary bureaucratic organizations as diverse as universities and development NGOs there is a continuous demand for assessment and evidence that goals are being realized with the rise of "audit culture" (Strathern 2000) or "audit society" (Power 1997). Thus in countertrafficking programs - generally funded by international agencies and implemented by NGOs — the lack of a statistical baseline creates particular problems, since "agencies cannot readily commit their allocated resources to the issue of trafficking unless they can establish from reliable data that their actions and interventions will actually resonate on the ground" (Makkai and McCusker 2004: 66).

In this essay I am interested neither in disputing nor in affirming the various figures that circulate concerning human trafficking, nor even in engaging in discussions about the extent of this market, but rather in understanding how auditing sets into motion a particular regime of action and evidence centered on film. Thus I want to consider how human trafficking, particularly of women and children into prostitution, is "established" (see the quote from Makkai and McCusker above) as a "market" not with tools such as statistics but through feature films, investigative news reports, and documentaries such as Buying and Selling Children and Women. It is notable that in the past few years there has been a veritable explosion in the number of countertrafficking films, which have come to shape public perceptions of trafficking (Soderlund 2005; Vance 2005; Andrijasevic 2007). For instance, the International Justice Mission became one of the most successful and widely recognized Christian countertrafficking organizations in the United States through "rescue missions" in collaboration with television journalists (Bernstein 2007: 139).

Thus I refuse to take human trafficking for granted as a market, instead following Michel Callon's (1998) argument that economies are an outcome of eco- 
nomics. In other words, my direct concern is not with the trafficking of human beings per se but with the technologies - and the knowledge, power, and financial resources that sustain them (Elyachar 2005) — through which a particular kind of black market is constituted, one that governments and organizations around the world have made it a priority to destroy in the global "war on trafficking." There are two reasons for this shift of attention. First, the extensive use of moving images in countertrafficking is empirically striking in itself and bears no direct relation with the actual forms of violence that many migrants experience. Second, "human trafficking" has a depoliticizing function through the concern with — and intervention on behalf of - a particular type of migrant, namely, the "victim," rather than broader issues such as labor rights and the freedom of mobility. As such, the enduring effect of trafficking interventions may prove to be the suppression and intensifying regulation of migration rather than the protection of migrants themselves.

In this process there is an increasing disconnect between the construction of "trafficking" as a market that demands intervention and the various forms of migrant experience that characterize the contemporary world. More specifically, it is the expansion of audit as a neoliberal technology that largely generates this disconnect, thus constituting trafficking as an object and setting into motion particular forms of action within a self-referential system. From this perspective, I argue - although this is clearly beyond the scope of this essay - that what is needed is not more evidence about particular types of victims but, rather, a complete reframing of debates concerning the relationship between migration and exploitation.

\section{Auditing, Trafficking, and Image Management}

Since 2002 Batam has become an exemplary site in the production of a geographical imaginary of human trafficking, as migrants and tourists have come to converge in the island's extensive sex industry. In this context, films about trafficking have been made that converge in terms of both forms and content. Most notably, each features testimonials of victims and interviews with NGO workers who describe the problem. However, the individuals and organizations that make the films vary significantly; they include not only the explicitly feminist Indonesian NGO YJP but also Shared Hope from the United States, founded and run by former Republican congresswoman Linda Smith; a production house on contract for the English Channel 4 series Unreported Worlds; Chinese- and English-speaking Singaporean television stations; Hong Kong-based Star TV; 
Indonesian SCTV; and an Australian journalist who made a documentary film in which two women were "rescued" and escorted back to their home villages. The film screened on the Australian Broadcasting Corporation, and a snippet was later shown on The Oprah Winfrey Show in the United States. ${ }^{2}$

But it is not immediately obvious why film has acquired such an important position in contemporary countertrafficking campaigns. ${ }^{3}$ The often-expressed need and demand for testimonials of trafficking victims are certainly one way of understanding this process. In contrast, Michael Power's incisive critique of auditing (1997: 147), which he terms "rituals of verification" and identifies as a "new form of image management," suggests a more unexpected starting point for understanding the emergence of this need: the links between transnational funding circuits and film. Following from this point, the essay begins to map an emergent transnational sociology of actors and affective relationships that are involved in the production and circulation of films such as Buying and Selling Children and Women and bound together through the constitution of trafficking as a problem — what Margaret Keck and Kathryn Sikkink (1999) call "transnational issue networks."

In this process, a humanitarian media complex has formed that is by no means homogeneous or stable through space and time, but uses the testimonial of the trafficking victim along with accounts and support from mediating NGOs, to produce what Carol Vance (2005) identifies as the dominant form of trafficking film, the melomentary, or melodramatic documentary. This is in keeping with the growing importance of testimony in human rights advocacy since the 1990s (McLagan 2003). As publicity has become "the structuring principle of activist politics" (McLagan 2005: 228), film has become the critical vehicle for testimony.

I should state explicitly here that I am not situating myself as an "anthropologist as witness" (Marcus 2005). It would certainly not be difficult for me to discover and reveal the plight of victims on Batam - a place where I have conducted extensive ethnographic research since the late 1990s (Lindquist 2009) - thereby offering a singular contribution to the formation of human trafficking as a global problem. In contrast, I am arguing that if one wants to conceptualize human trafficking as a market that demands intervention in humanitarian terms, then one

2. For an extended clip of the film, see www.youtube.com/watch?v=szKqtiKmbC 8 (accessed July 3, 2008).

3. But it is worth comparing with films concerning the white slave trade from the 1910s (Campbell 2006: 14-18). 
should begin not in particular places such as Batam but, rather, with the historically situated transnational system through which intervention is deemed necessary (see Castel 1991). In the following I begin to track this process in ethnographic terms.

\section{Regimes of Auditing}

Many NGOs in Indonesia that were engaged in HIV/AIDS prevention work during the 1990s - particularly those focusing on female prostitutes - have since the early 2000s shifted their attention to trafficking issues. One example is YMKK on Batam. With a primary focus on women's reproductive health, YMKK was well situated to become a key actor when HIV emerged as an issue on Batam, primarily through a World Bank project in the late 1990s. More recently, YMKK has become involved in a series of countertrafficking programs as it has been approached by donors offering support and funding. Notably, the various projects YMKK has implemented - reproductive health, HIV/AIDS, and trafficking share "female sexuality" as their object of intervention and have tended to overlap in practice.

As with other Indonesian NGOs that have become dependent on the ebb and flow of funding, the number of staff has varied depending on economic circumstances. In 2006 YMKK's fourteen staff members, of whom five were "outreach workers," approached and gained the trust of the two main "target groups," female factory workers and prostitutes, and distributed information about reproductive health issues. Outreach workers also collect information from the women: their name, age, address, phone number, details about menstruation cycles, frequency of sexual activity, numbers of sexual partners, history of sexually transmitted infections, and use of contraceptives and, finally, their signature. Significantly, YMKK began to add questions concerning trafficking after 2002, in an attempt to identify how women had entered prostitution and whether they had been coerced or tricked and wished to exit.

The bulk of the outreach work is spent collecting these data, which are later entered into computers in YMKK's office. Creating lists with the women's signatures is absolutely critical since target goals are achieved by informing a certain number of women each week. The director of YMKK — who has a master's degree from an elite Indonesian university - spends much of her time writing (most often in English) either grant proposals or evaluation reports for donors, and to a large degree the organization's success in securing funding has depended on her language and writing skills. YMKK's main concern, therefore, has been to 
create a geography of risk through surveys, data entry, and evaluation reports to donors, rather than to directly intervene.

The production of documents that circulate and are evaluated is critical to a form of auditing culture that is pervasive in development work today. In fact, terms directly connected with auditing such as accountability and transparency are often in practice calls to documentation (Riles 2006: 6). However, as Marilyn Strathern (2006: 190) notes, more than strictly a process of evaluation, audit is an "enabling mechanism" that "creates perturbations on the boundaries of organizations it activates them by making them perform in public."

Thus, if auditing is a system that is both expansive - welcoming new technologies and collaborations - and a form of "image management," this suggests how film fits well with contemporary countertrafficking campaigns. On the one hand, since statistical evidence is inherently problematic, moving images become a mode of representation that creates evidence that there is a trafficking problem and that something must be done about it. On the other hand, these films become documents in their own right that come to circulate among organizations and to a broader public. Therefore film appears as a technology that begins to resolve particular problems within the transnational field of organizations that deal with human trafficking. Like photographs, these films become "a species of alchemy, for all that they are prized as a transparent account of reality" (Sontag 2003: 81). In this process, countertrafficking films expand the sphere of auditing while remaining strictly within the realm of its logic.

\section{Producing Trafficking}

Tracking the rumor of trafficking demands connections. As journalists and filmmakers from major cities like Jakarta and Singapore have traveled to Batam to create particular documents - namely, films about human trafficking - NGOs have become obvious points through which to access victims. NGOs like YMKK in marginal places such as Batam do not usually deny visitors from the capital or abroad. Even if they sometimes ponder the surge of interest in trafficking — "it's not like it's a new problem,"4 as one of them put it — or consider the dilemmas of becoming dependent on funding cycles, they have learned the importance of being part of a network that offers friendship, funding, and information (cf. Riles 2000). It is precisely these types of interactions - often transnational in form - rather

4. Husaini Tarmizi, outreach worker at YMKK, personal communication with the author, Batam, Indonesia, June 26, 2006. 
than the intentions of individual actors and organizations that come to shape the form that countertrafficking takes.

Gadis was the first to admit that the YJP filmmakers were neophytes when they shot Buying and Selling Children and Women. YMKK's outreach workers were with them most of the time, escorting them to brothel villages and discos and introducing them to the women who were interviewed in the film. The actual shooting of the film was relatively uncomplicated even if the filmmakers at times felt threatened by "thugs" (preman). Rather, it was the editing that was particularly difficult and where they desperately needed support. Back in Jakarta it was therefore reasonable that they turn to Imelda Salajan, a former BBC journalist with extensive editing and production experience who ran media-training workshops for journalists and NGOs.

"When I saw the first version of Buying and Selling Children and Women," Imelda told me while shaking her head, "it was a complete mess." In particular, she did not like the language YJP was using. "They wanted to call the women in the field 'survivors,' but in the context of the film they were 'victims.' 'Survivor' seemed silly; it was an NGO term. I said that they should call them what they were." 5 What they were became clear in the final version of the film, as the English subtitles identified the prostitutes as "sex slaves."

For the observant bilingual viewer there is at this point in the film a startling translation, as the Indonesian subtitles introduce the women as pekerja seks, literally "sex worker." The use of "sex slave" is not surprising, since it is a common term in countertrafficking discourse (Bales 2005). However, YJP was worried that the literal translation of the term would lead to a public outcry that Indonesia is not a backward country where slavery still exists. Instead, they chose to use pekerja seks, which had entered Indonesian in the 1990s through international NGOs and was a term that describes the kind of activism that YJP pursues, one that is concerned with "women's empowerment" (pemberdayaan perempuan).

Thus YJP was engaging with two different audiences, one primarily transnational and concerned with showing how the trafficking of women and children into prostitution was a form of slavery and a major problem in Indonesia - the realm of donors and auditing - and the other primarily national and more generally concerned with drawing attention to the plight of female labor migrants in Indonesia. Yet when I talked with Gadis about the film, I told her that I felt that beyond the attempt to speak to two different audiences the film ultimately collapsed into a conservative message since it explicitly stated that women should 
stay at home, which I took to mean that they should not become migrants because they could not trust that they would not become trafficked. How, I asked, was this position reconcilable with the organization's explicit politics of women's empowerment? Gadis was initially upset by my claim of conservatism and argued that this was not YJP's message. But after discussing the matter for a while she finally agreed and explained that they had been "caught" in a particular process of editing. Importantly, it was clearly not possible to present "trafficking" in any other way than as a tragedy in which the women and children were "victims." In fact, it is through this narrative structure that trafficking takes shape both as a form of cross-cultural communication and a transnational infrastructure of organizations and actors.

Meg McLagan (2005: 229) notes that film festivals are sites where human rights-oriented documentary films transform audiences "into witnesses and in some instances activists." Films such as Buying and Selling Children and Women rarely make it to festivals. They circulate in the realm of NGO activities and the organizations that fund them. For Saleemah at UNIFEM, it is the "real-life biting value" of the prostitutes' testimonials on Batam that are crucial in the actual use of the film and their attempts to inform and motivate audiences. They create shock and surprise, Saleemah claims, particularly the "mechanical parts" in which one of the young prostitutes explains the everyday sexual activities she is engaged in. 6

Through their various encounters with Buying and Selling Children and Women, both Imelda's NGO, Ontrack Media, and UNIFEM Singapore have increasingly realized the value of film and come to facilitate the work of foreign journalists and filmmakers who come to Indonesia to investigate trafficking. They are inevitably sent to "grassroots organizations" such as YMKK, and their visits take a standard form, which includes the search for elements critical to the genre of the trafficking film. Visitors ask to be escorted to "red light districts," most often a brothel village or a karaoke bar. At the center of these reports are interviews with prostitutes, preferably the youngest available, who frequently are members of YMKK's target groups. They then interview Lola at her office or when she is speaking in public. Most ask the same questions. How many cases of trafficking are there on Batam? Are the numbers going up or down? But according to Lola, it is not possible to adequately respond, since "we are not a research institute." 7 Yet in the context of contemporary forms of countertrafficking, this

6. Ismail, interview by the author.

7. Lola Wagner, interview by the author, Batam, Indonesia, August 12, 2006. 
is a role that YMKK and other NGOs must consider carefully, as they come to traffic in information.

\section{Auditable Victims}

Although some frequently argue that the trafficking in women and children is increasing dramatically in Southeast Asia and across the globe, others note that there is "no reliable direct evidence of the trade growing or declining, and there exist no reliable, academically rigorous attempts to quantify or value the trade in humans." 8 The questionable origins of statistics are obvious on Batam and across Indonesia. The United Nations International Children's Emergency Fund (UNICEF) Indonesia claims that one hundred thousand children are trafficked in Indonesia each year, but the basis for this claim is not substantiated. ${ }^{9}$ Figures circulate in news reports that vary dramatically in terms of the numbers of prostitutes, underage trafficking victims, and how many Singaporean men visit the island. YMKK is often cited as a source of data, while it in turn cites figures from international organizations such as UNICEF.

In this context, it is instructive to compare countertrafficking and HIV/AIDS prevention campaigns. The anticipated HIV/AIDS pandemic has not created the same demand for testimonials that trafficking has. Arguably, one reason for this is the force of epidemiology as a scientific model, which has legitimated and formed the basis for interventions across the world. In fact, HIV/AIDS has largely been constituted as a problem through epidemiological models; some claim that "epidemiological research and intervention strategies are two sides of the same coin" (Adams and Pigg 2005: 20).

Because of the lack of statistical data, there is arguably a similar relationship between trafficking testimonials and intervention strategies. On the one hand, testimonials offer a form of truth claim that aims to create affect, thereby motivating the viewer to act. On the other hand, they become a form of evidence that the trafficking of women and children is happening and that something must be done. If epidemiology (and quantification more generally) is a "technology of distancing" (Porter 1995: ix), the trafficking testimonial moves more ambiguously between

8. United Nations Office on Drugs and Crime, "Human Trafficking: Regional Profile 200303-11," www.unodc.un.or.th/material/document/RegionalProfile.pdf (accessed December 5, 2005). See also Agustín 2007: 38.

9. See UNICEF Indonesia, "Factsheet on Commercial Sexual Exploitation and Trafficking of Children," www.unicef.org/indonesia/Factsheet_CSEC_trafficking_Indonesia-pdf (accessed May 20, 2008). 
proximity and distance, as it comes to generalize a qualitative event. Since testimonials are at the center of a kind of science of countertrafficking, moving images have become the medium that allows for their circulation.

Several observers have noted the relationship between audit culture and a global process of virtualization, in which neoclassical economics has become a dominant model for understanding and acting on the world. For instance, Daniel Miller (1998: 204) states that "auditing is a sign of a shift to political virtualism." John Gledhill (2004: 341) in his discussion of neoliberalism and the spread of audit culture to development agencies and NGOs claims that what is "really being evaluated is the procedural efficiency of action in terms of the agency's mission rather than its substantive impact on the lives of human beings," a form of virtualization that characterizes neoliberalism more broadly. In other words, the model that is constituted through the agency's mission becomes the basis for the production of a particular form of reality.

In countertrafficking campaigns, the media play a role that may be unprecedented in the context of modern forms of "global compassion" (Höijer 2004). Certainly, if we pay attention to the Ethiopian famine of the 1980s and the 2004 tsunami disaster, moving images played a crucial role in generating engagement in both emotional and economic terms (Moeller 1999). However, there is arguably a different form of image management at work in the context of countertrafficking campaigns. Films that use testimonials of women and children identified as victims should be considered in the context of the spread of auditing practices to development and humanitarian projects. The work of organizations such as YMKK is to a large degree about producing lists that can be shown as proof of procedural efficiency. Yet merely convincing on the level of technical procedure is not enough. To generate funding and action there must be a commitment on a programmatic level, which demands other forms of evidence (Power 1997: 6-7) that are made public through countertrafficking films. The organizations I have described are dependent on the enduring public interest in trafficking. Thus in this process the testimonial of the victim becomes a necessity in the formation of an aesthetic of trafficking. If there is today a "war on trafficking," then it may be worthwhile to recall Virilio's (1989: 6) claim that "there is no war without representation."

But the production of representations and virtualism, more broadly, are material processes that involve particular forms of labor (Ginsburg et al. 2002: 19), and "the act of making public" is "a processual event" (McLagan 2005: 224; emphasis in the original). In this essay I have begun to describe the wide range of 
actors and funding relationships involved in the making of one particular countertrafficking film and the process whereby trafficking becomes imagined as a market of sorts. This process, in turn, allows for particular types of collaboration and communication across borders and between organizations of radically different political persuasion. However, the confusion that NGO workers on Batam felt regarding the dramatic interest in trafficking and the discomfort that Gadis experienced when she found it impossible to stray from a narrative of victimization suggest a process of depoliticization that sets strict limits for intervention.

Auditing and countertrafficking share a commitment to ideals - particularly ones related to ethics - that are nearly impossible to criticize in principle (cf. Strathern 2000: 5). How can one not support processes of transparency and accountability? How can one not be against sexual slavery? Yet in the move toward coherent narratives and a language of generalization there is the risk of premature closure and thereby the avoidance of more complicated political issues as well as discussions concerning the potentially negative consequences of humanitarian interventions. It is these processes that need to be interrogated more carefully, not through an engagement with countertrafficking but through a concern with the forces that come to shape "trafficking" as a market that we believe we understand and feel compelled to destroy.

\section{References}

Adams, Vincanne, and Stacey Leigh Pigg. 2005. Introduction: The moral object of sex. In Sex in development: Science, sexuality, and morality in global perspective, edited by Vincanne Adams and Stacey Leigh Pigg. Durham, N.C.: Duke University Press.

Agustín, Laura María. 2007. Sex at the margins: Migration, labour markets, and the rescue industry. London: Zed.

Andrijasevic, Rutvica. 2007. Beautiful dead bodies: Gender, migration, and representation in anti-trafficking campaigns. Feminist Review 86: 24-44.

Bales, Kevin. 2005. Understanding global slavery: A reader. Berkeley: University of California Press.

Bernstein, Elizabeth. 2007. The sexual politics of the "new abolitionism." differences: A Journal of Feminist Cultural Studies 18, no. 3: 128-51.

Callon, Michel. 1998. Introduction: The embeddedness of economic markets in economics. In The laws of the market, edited by Michel Callon. Oxford, U.K.: Blackwell. 
Campbell, Russell. 2006. Marked women: Prostitutes and prostitution in the cinema. Madison: University of Wisconsin Press.

Castel, Robert. 1991. From dangerousness to risk. In The Foucault effect: Studies in governmentality, edited by Graham Burchell, Colin Gordon, and Peter Miller. Chicago: University of Chicago Press.

Elyachar, Julia. 2005. Markets of dispossession: NGOs, economic development, and the state in Cairo. Durham, N.C.: Duke University Press.

Ginsburg, Faye D., Lila Abu-Lughod, and Brian Larkin, eds. 2002. Introduction to Media worlds: Anthropology on new terrain. Berkeley: University of California Press.

Gledhill, John. 2004. Neoliberalism. In A companion to the anthropology of politics, edited by David Nugent and Joan Vincent. London: Blackwell.

Höijer, Birgitta. 2004. The discourse of global compassion: The audience and media reporting of human suffering. Media, Culture and Society 26: 513-31.

Keck, Margaret, and Kathryn Sikkink. 1999. Transnational advocacy networks in international and regional politics. International Social Science Journal 51: 89-101.

Kempadoo, Kamala, with Jyoti Sanghera and Bandana Pattanaik, eds. 2005. Trafficking and prostitution reconsidered: New perspectives on migration, sex work, and human rights. Boulder, Colo.: Paradigm.

Laczko, Frank. 2005. Data and research on human trafficking. International Migration 43, nos. 1-2: 5-16.

Levitt, Steven, and Sudhir Venkatesh. 2000. An economic analysis of a drugselling gang's finances. Quarterly Journal of Economics 115: 755-89.

Lindquist, Johan. 2009. The anxieties of mobility: Development and migration in the Indonesian borderlands. Honolulu: University of Hawai'i Press.

Makkai, Toni, and Rob McCusker. 2004. What do we need to know? Improving the evidence base on trafficking in human beings in the Asia-Pacific region. Development Bulletin 66: 36-42.

Marcus, George. 2005. The anthropologist as witness in contemporary regimes of intervention. Cultural Politics 1, no. 1: 31-49.

McLagan, Meg. 2003. Human rights, testimony, and transnational publicity. Scholar and Feminist Online 2, no. 1. www.barnard.edu/sfonline/ps/mclagan.htm.

2005. Circuits of suffering. PoLAR: Political and Legal Anthropology Review 28: 223-39.

Miller, Daniel. 1998. Conclusion: A theory of virtualism. In Virtualism: A new political economy, edited by James Carrier and Daniel Miller. Oxford: Berg. 
Moeller, Susan D. 1999. Compassion fatigue: How the media sell disease, famine, war, and death. New York: Routledge.

Porter, Theodore M. 1995. Trust in numbers: The pursuit of objectivity in science and public life. Princeton, N.J.: Princeton University Press.

Power, Michael. 1997. The audit society: Rituals of verification. Oxford: Oxford University Press.

Riles, Annelise. 2000. The network inside out. Ann Arbor: University of Michigan Press.

2006. Introduction: In response. In Documents: Artifacts of modern knowledge, edited by Annelise Riles. Ann Arbor: University of Michigan Press.

Savona, Ernesto Ugo, and Sonia Stefanizzi, eds. 2007. Measuring human trafficking: Complexities and pitfalls. New York: Springer.

Soderlund, Gretchen. 2005. Running from the rescuers: New U.S. crusades against sex trafficking and the rhetoric of abolition. NWSA Journal 17, no. 3: 64-87.

Sontag, Susan. 2003. Regarding the pain of others. London: Hamish Hamilton.

Strathern, Marilyn, ed. 2000. Audit cultures: Anthropological studies in accountability, ethics, and the academy. London: Routledge.

2006. Bullet-proofing: A tale from the United Kingdom. In Documents: Artifacts of modern knowledge, edited by Annelise Riles. Ann Arbor: University of Michigan Press.

Vance, Carol. 2005. "Juanita/Svetlana/Geeta" is crying: Melodrama, human rights, and anti-trafficking interventions. Lecture presented at Stockholm University, November 12.

Virilio, Paul. 1989. War and cinema: The logistics of perception, translated by Patrick Camiller. London: Verso. 